\title{
Erratum to: The effects of biological geotextiles on gully stabilization in São Luís, Brazil
}

\author{
A. J. T. Guerra' ${ }^{1}$ J. F. R. Bezerra ${ }^{2}$ M. A. Fullen ${ }^{3}$. \\ J. K. S. Mendonça ${ }^{4}$ M. C. O. Jorge ${ }^{1}$
}

Published online: 9 July 2015

(C) Springer Science+Business Media Dordrecht 2015

\section{Erratum to: Nat Hazards (2015) 75:2625-2636 \\ DOI 10.1007/s11069-014-1449-0}

The article: The effects of biological geotextiles on gully stabilization in São Luís, Brazil, A. J. T. Guerra, J. F. R. Bezerra, M. A. Fullen, J. K. S. Mendonça, M. C. O. Jorge, Nat Hazards (2015) 75: 2625-2636, DOI 10.1007/s11069-014-1449-0 belongs to the Special Issue: Gully Erosion as a Natural Hazard.

The online version of the original article can be found under doi:10.1007/s11069-014-1449-0.

$\triangle$ A. J. T. Guerra

antoniotguerra@gmail.com

1 LAGESOLOS, Department of Geography, Federal University of Rio de Janeiro, Ilha do Fundão, Cidade Universitária, Rio de Janeiro 21940-590, Brazil

2 Department of Geography, State University of Maranhão, São Luis, Brazil

3 School of Applied Sciences, The University of Wolverhampton, Wolverhampton WV1 1SB, UK

4 Socioeconomic and Cartographic Studies Institute of Maranhão State, São Luis, Brazil 